\title{
Article \\ Testing for Wearability and Reliability of TPU Lamination Method in E-Textiles
}

\author{
Paula Veske*(D), Frederick Bossuyt and Jan Vanfleteren (D) \\ Centre for Microsystems Technology (CMST), Imec and Ghent University, Technologiepark 126, \\ 9052 Gent, Belgium; frederick.bossuyt@ugent.be (F.B.); Jan.Vanfleteren@UGent.be (J.V.) \\ * Correspondence: paula.veske@ugent.be
}

\begin{abstract}
Electronic textiles (e-textiles) and wearable computing have been emerging increasingly during the last decade. Since the market interest and predictions have grown, the research into increasing reliability and durability of wearables and e-textiles is developing rapidly. The washability of different integration methods and resistance to mechanical stress are the main obstacles being tackled. However, the freedom of movement and overall comfort is still often overlooked during the development phase. It is essential to see the e-textile product as a whole and consider several aspects of user experience. This work will focus on developing and improving the thermoplastic polyurethane (TPU) lamination integration method for e-textiles. In the work, a stretchable copperpolyimide based circuit was laminated onto knit fabric using various TPU films and stacks. The study shares measurable characteristics to determine which material assembly and design would ensure the highest durability for the electronics part without losing its original textile softness, flexibility and stretchability.
\end{abstract}

Keywords: e-textiles; stretchable electronics; wearables; packaging; washing reliability

Citation: Veske, P.; Bossuyt, F.; Vanfleteren, J. Testing for Wearability and Reliability of TPU Lamination Method in E-Textiles. Sensors 2022, 22, 156. https://doi.org/10.3390/ s22010156

Academic Editors: Norbert Herencsar and Khaled N. Salama

Received: 2 December 2021

Accepted: 24 December 2021

Published: 27 December 2021

Publisher's Note: MDPI stays neutral with regard to jurisdictional claims in published maps and institutional affiliations.

Copyright: (C) 2021 by the authors. Licensee MDPI, Basel, Switzerland. This article is an open access article distributed under the terms and conditions of the Creative Commons Attribution (CC BY) license (https:// creativecommons.org/licenses/by/ $4.0 /)$.

\section{Introduction}

The wearables and smart textile market have been growing exponentially during the last decade. The following 5-10 years are predicted to be fast-paced in growth by several market reports and funding bodies [1-3]. E-textiles' readiness for the market also depends significantly on the user's attitude towards wearing and using them. Reliable but uncomfortable garments or vice versa can be unacceptable for the public, as seen in the currently small amount of e-textile products available.

While the smart textiles gathered traction already in the early 1990s, it was the early 21st century when Leah Buechley and Mike Eisenberg collaborated with SparkFun Electronics to develop Lilypad Arduino that could be used for sewing electronics easily on garments and other textile goods [4]. Now, smart textiles (including e-textiles) are most commonly defined as fabrics or garments that have technology that senses and reacts to the environment to which it is exposed. As a result, the wearer will be able to experience "increased functionality" [5]. While "increased functionality" is indeed essential, the durability and the comfort of the product are also aspects that define the product's popularity.

One of the most researched areas in e-textiles is reliability against domestic washing procedures and finding the most durable solution. While one of the biggest obstacles to doing such research uniformly is lack of standardization for e-textiles washability testing, the most commonly used references are:

- ISO (International Organization for Standardization) standard "ISO 6330:2012-TextilesDomestic washing and drying procedures for textile testing".

- $\quad$ AATCC (American Association of Textile Chemists and Colorists) standard "AATCC 135-Test Method for Dimensional Changes of Fabrics after Home Laundering”. [6,7]. 
Various effects due to laundering are being checked in current research in different aspects, e.g., stability of electrical properties (change in resistance, etc.) or stability of the functionality overall [8-12]. One of the techniques for making e-textiles durable is laminating conductive or functional parts with TPU films [13-16]. This method can be highly efficient by using continuous roll press during manufacturing, which is already available in most textile and garment productions. Thus, considering lamination as an encapsulation method for smart textiles is highly relevant.

However, when incorporating electronics, such as sensors and actuators, in the garments, they need to keep the same or similar level of stretchability, flexibility, softness and sensitivity against the skin-their comfort. Comfort is difficult to define, but it is mainly described as a harmonious state between humans and the environment [17]. However, since personalisation and everyday well-being are a growing trend, "comfort" is also examined through other sensations, such as freedom of movement and psychological and sensorial comfort [18-20]. Moreover, comfort in wearables has been researched to some extent, where the relationship between functionality and comfort is often studied [21-23]. Knight et al. [24] even developed a "comfort assessment tool" for wearables where by using comfort rating scales (CRS), six aspects are considered: emotion, attachment, harm, perceived change, movement and anxiety. It would be valuable to have some perception of possible (dis)comfort which the end-user can experience wearing e-textiles already during early phases of development. Sensorial discomfort can be ruled out by designing electronic parts not to touch the skin. Thus, it leaves the "freedom of movement" constriction that may be hugely affected by the integration method.

This work focuses on finding the balance between the comfort and reliability of etextiles. The current research is an extension of a previous study based on laminating a copper-polyimide bus system with different thermoplastic polyurethane (TPU) films and stacks on knit fabrics and conducting reliability (washing) tests on the samples [25]. This study also focuses on increasing comfort (freedom of movement) by higher stretchability and reliability in thinner TPU stacks by reducing the TPU area. Results will present measurable characteristics for freedom of movement based on tensile tests [26]. In addition, additional domestic washing cycles based on ISO 6330-2012 standard were executed for reliability tests [7].

\section{Materials and Methods}

The work consists of two main parts:

1. Wearability: Testing for freedom of movement

2. Reliability: Testing for washing reliability

The materials and sample concept always stayed the same. Used materials are listed in Table 1. Overall, the materials were categorized into three types: textile, electronic and integration materials.

Textile. Knit fabric from Eurojersey with high elasticity was always used as a textile carrier. Fabric can be typically used for several applications, such as sportswear, underwear and swimwear. Textile swatches' (used in the tests) longer edge was always cut along the warp thread. For wearability tests, the same size $(300 \mathrm{~mm} \times 60 \mathrm{~mm})$ swatches as for integrated samples were cut.

Electronics. The electronics consist of a flexible printed 4-track $\mathrm{I}^{2} \mathrm{C}$ bus system with 3 interposer islands, and meander-shaped interconnects in the test system. Copper tracks on the polyimide-copper base sheet were etched with $\mathrm{H}_{2} \mathrm{SO}_{4}$ with standard lithography technique. The circuit was then laminated with ShengYi SF305C coverlay, which had perforations that allowed contact with the copper. Finally, the tracks were cut from the sheet using a $\mathrm{CO}_{2}$ laser. The copper-polyimide meander design was chosen based on previous work, proving the best durability and low electrical resistance [25]. The meander design also included an additional copper track at the top and the bottom parts for reinforcement purposes only; these 2 tracks were not electrically connected to the circuit (Figure 1a). For mimicking stiff connections to rigid electronics, printed circuit boards (PCBs) were 
connected to the two edge interposer islands using SAC305 solder paste and reflown in a vapour phase reflow oven (IBLSLC 300) at $250{ }^{\circ} \mathrm{C}$.

Table 1. Materials overview.

\begin{tabular}{|c|c|c|}
\hline Material & Dimensions & Characteristics \\
\hline $\begin{array}{l}\text { Eurojersey Sensitive }{ }^{\circledR} \text { Fit ( } 68 \% \text { microfibre polyamide, } \\
32 \% \text { elastane) }\end{array}$ & Weight $213 \mathrm{~g} / \mathrm{m}^{2}$, sample size $300 \times 60 \mathrm{~mm}$ & Knit fabric \\
\hline $\begin{array}{l}\text { Etched copper-polyimide 4-track meander } \\
\text { bus system }\end{array}$ & $18 \mu \mathrm{m} \mathrm{Cu}, 50 \mu \mathrm{m}$ PI (polyimide film) & \\
\hline Polyimide based Coverlay film ShengYi SF305C & $25 \mu \mathrm{m}$ thickness & \\
\hline $\begin{array}{l}\text { Printed circuit board (PCB) with } 4 \text { gold-plated } \\
\text { connection pads } \\
\text { SAC } 305 \text { solder paste- }-96.5 \% \text { tin, 3\% silver, and } \\
0.5 \% \text { copper }\end{array}$ & $14 \times 12.5 \times 0.2 \mathrm{~mm}$ & \\
\hline TPU film Bemis 3914 & $100 \mu \mathrm{m}$ thickness & $\begin{array}{l}\mathrm{E}=2.2 \mathrm{Mpa}, \\
\text { glue line temp } 120-170{ }^{\circ} \mathrm{C}\end{array}$ \\
\hline TPU film Prochimir TC5011 & $250 \mu \mathrm{m}$ thickness & $\begin{array}{l}\mathrm{E}=28 \mathrm{MPa}, \\
\text { glue line temp } 140-170{ }^{\circ} \mathrm{C}\end{array}$ \\
\hline
\end{tabular}

Integration materials. For integrating the electronics system onto the textile, two different TPU films were tested. Stretchable Bemis 3914 (thickness $100 \mu \mathrm{m}$ ) and Prochimir TC5011 (thickness $250 \mu \mathrm{m}$ ) TPU films were used in single and stacked versions. TPU was cut in the shape of the meander circuit to increase the freedom of movement. The film area was increased more around the interposer islands and a few millimetres around the meander bus tracks (Figure 1a,b,d).

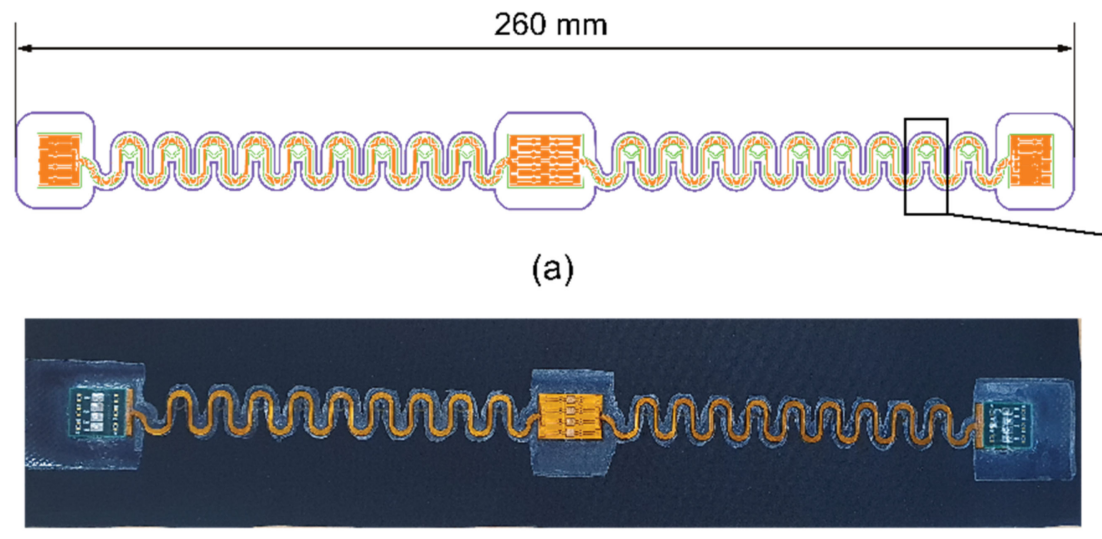

(b)

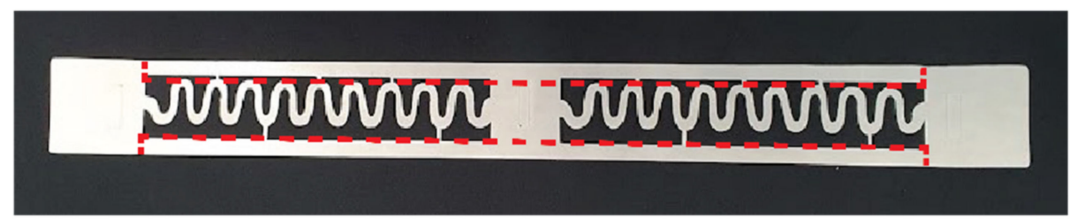

(c)

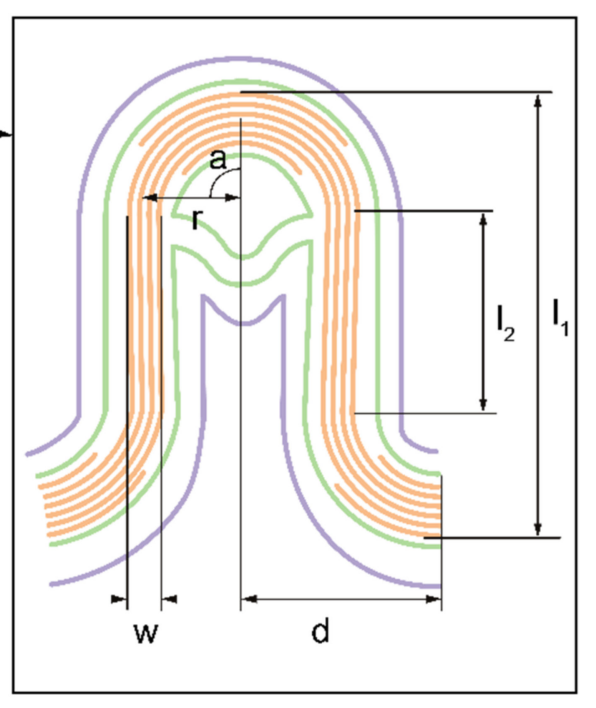

(d)

Figure 1. Sample set-up. (a) Test batch sample outline: purple line TPU; green line coverlay; orange lines copper. (b) Test batch sample design V1 on the Eurojersey swatch fabric sized $300 \times 60 \mathrm{~mm}$. (c) TPU meander on white release paper with the frame. The red dotted line indicates where the frame is cut off before lamination on the fabric. (d) Close-up of the meander shape and measurements (see Table 2). 
Table 2. Meander dimensions based on Figure 1d.

\begin{tabular}{cccc}
\hline Mark & Description & Measurement & Unit \\
\hline $\mathrm{l}_{1}$ & Width of the meander bus & 11.4 & $\mathrm{~mm}$ \\
$\mathrm{I}_{2}$ & The length of the straight part connecting the top and bottom arc & 4.8 & $\mathrm{~mm}$ \\
$\mathrm{w}$ & Total width of meander including 4 Cu tracks & 0.9 & $\mathrm{~mm}$ \\
$\mathrm{~d}$ & Half of the period between the middle top and middle bottom part & 5 & $\mathrm{~mm}$ \\
$\mathrm{r}$ & Meander radius & 2.45 & $\mathrm{~mm}$ \\
$\mathrm{a}$ & Meander angle & 90 & 0.1 \\
& Spacing between copper tracks & 150 & $\mathrm{~mm}$ \\
& Copper track width & $\mu \mathrm{m}$ & \\
\hline
\end{tabular}

Four different versions of sample batches were prepared for each test (Table 3). Every batch consisted of 5 identical samples. Thus, 20 samples were prepared for both wearability and reliability test. The overall process for sample batches preparation was:

1. Preparation of electronics and stretchable copper-polyimide meander system;

2. Preparation of fabric swatches and TPU film layers in the shape of the copperpolyimide meander system;

3. Sandwiching the copper-polyimide meander system between the TPU layers in 4 versions (Table 3);

4. Laminating the sandwiched copper-polyimide meander system onto the knit fabric swatches.

The first two steps (preparation of electronic circuit, fabric swatches and TPU) is explained above with material descriptions. In the third step, the TPU film layers were used to sandwich the copper-polyimide stretchable circuit for encapsulation and laminate onto the knit fabric. Since the TPU was cut in the shape of the meander interconnects (Figure 1), the handling of thinner $100 \mu \mathrm{m}$ Bemis TPU film was more complex than the thicker Prochimir film. Thus, a frame around the meander circuit was created (Figure 1c). The frame was cut off before laminating the sandwiched (encapsulated) circuit onto the fabric swatch, as shown by the red dotted line in Figure 1c.

Table 3 indicates the entire thickness of TPU layers (on the front and backside of the electronic circuit) before the lamination process and after. The last TPU thickness indicates how different the films' melting flow was, which is also reflected in the stretchability in the later stages. The lamination parameters used were $170{ }^{\circ} \mathrm{C}$ with 4 bar pressure for $40 \mathrm{~s}$. Lamination was done on a Hotronix ${ }^{\circledR}$ Air Fusion IQ ${ }^{\circledR}$ heat press where the heating plate is on the top and the bottom plate is at room temperature.

Wearability test method. The wearability or the freedom of movement test was based on ISO 20932-1:2018 standard for determining fabrics elasticity with a strip method [26]. Each sample with a laminated circuit was clamped to the Lloyd Instruments LS5 machine from the TPU area (not only from the textile) as seen on Figure 2.

Table 3. Samples overview.

\begin{tabular}{cccc}
\hline Sample Name & TPU Used & $\begin{array}{c}\text { Total TPU Thickness before } \\
\text { Lamination, } \boldsymbol{\mu m}\end{array}$ & $\begin{array}{c}\text { Total TPU Thickness after } \\
\text { Lam-ination, } \boldsymbol{\mu m}\end{array}$ \\
\hline Version 1, V1 & Bemis 3914 & 200 & 172 \\
Version 2, V2 & Bemis 3914 & 400 & 387 \\
Version 3, V3 & Prochimir TC5011 & 500 & 395 \\
Version 4, V4 & Prochimir TC5011 & 1000 & 747 \\
\hline
\end{tabular}




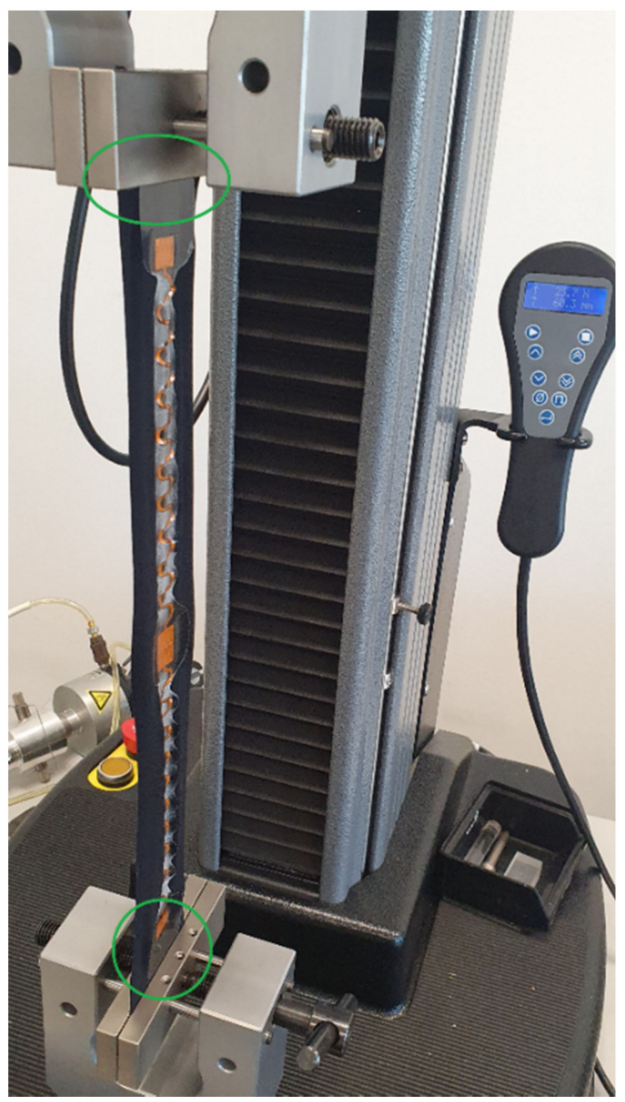

Figure 2. Stretched sample where the green circled areas highlight that the sample was clamped from the laminated fabric area and not just fabric.

The samples were stretched $20 \%$ of their length, held at the stretched position for $10 \mathrm{~s}$ and released (Figure 3). Each sample was stretched 100 cycles. Since strain was fixed, the primary measurement analysed was the load in different cycles and moments during the cycles. The bus system's functionality was checked with a multimeter before and after the test.

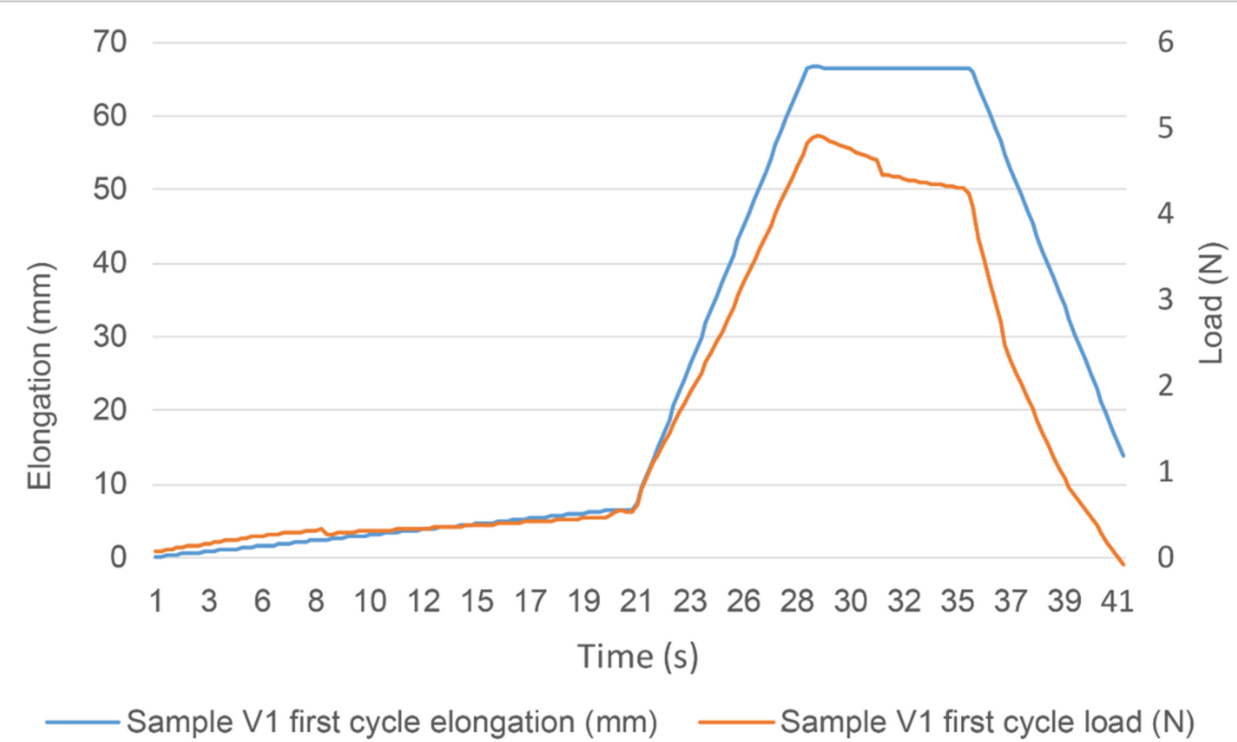

Figure 3. The tensile test one cycle overview, repeated 100 times. 
Reliability to domestic washing procedure method. Washability of samples was tested based on ISO 6330-2012 standard that defines domestic washing and drying procedures [7]. Table 4 gives an overview of the exact washing program used during the tests. Two kilograms of microfiber towels (Nabaji, 88\% PES, 12\% PA) were included in each washing cycle. The washing tests were performed in an Electrolux W465H professional washing machine. The samples were washed all together in a mesh washing bag.

Table 4. Washing test procedure overview based on ISO 6330-2012 standard.

\begin{tabular}{|c|c|c|c|c|c|}
\hline $\mathbf{N r}$ & Washing Phase & Time, min & Temperature, ${ }^{\circ} \mathrm{C}$ & $\begin{array}{c}\text { Spin, Rmp } \\
\text { (Revolutions per } \\
\text { Minute) }\end{array}$ & Water Volume, 1 \\
\hline 1 & Main wash, detergent nr 3 & 15 & 40 & 49 & 15 \\
\hline 2 & Rinse 1 & 3 & Coldwater & 49 & 19 \\
\hline 3 & Drain 1 & 8 & Coldwater & 49 & - \\
\hline 4 & Rinse 2 & 3 & Coldwater & 49 & 19 \\
\hline 5 & Drain 2 & 8 & Coldwater & 49 & - \\
\hline 6 & Rinse 3 & 3 & Coldwater & 49 & 19 \\
\hline 7 & Drain 3 & 8 & Coldwater & 49 & - \\
\hline 8 & Rinse 4 & 3 & Coldwater & 49 & 19 \\
\hline 9 & Drain 4 & 8 & Coldwater & 49 & - \\
\hline 10 & Spin & 5 & Coldwater & 1100 & - \\
\hline
\end{tabular}

The tests aimed to reach 25 washing cycles with no errors in the sample batch. All samples were washed simultaneously. In the previous tests [25], using textile-based circuits with $\mathrm{I}^{2} \mathrm{C}$, we had seen issues that the rise time of the $\mathrm{I}^{2} \mathrm{C}$ blockwaves is too slow. It was solved by tuning the pull-up resistors. As the rise time is depending on the resistance of the lines and the capacitance between them, we believe that due to washing the I2C signal quality is mainly affected by the resistance change. Furthermore, if the resistance of the tracks becomes too high, the voltage drop on the line will be too high. Sensors on the bus will not reach their necessary supply voltage and not function properly. Therefore, he each track's resistance was checked after every washing cycle with a multimeter. Following five successful washing cycles, measurements were taken every two washing cycles.

\section{Results}

Results were analysed in two parts as mentioned in the Materials and Methods section's beginning:

1. Wearability: Testing for freedom of movement

2. Reliability: Testing for washing reliability

Firstly, it was observed, the melting areas of stacks and TPUs differed, as seen in Table 3 last two columns. In V4, the thickness of the TPU area changed from $1000 \mu \mathrm{m}$ to $750 \mu \mathrm{m}$, whereas in V1, it changed from $200 \mu \mathrm{m}$ to $170 \mu \mathrm{m}$. Figure 4 presents V1 and V4 samples after lamination and tensile tests. The melting area of the TPU is significantly larger in V4 compared with V1. The circled areas on the figure show higher stress areas where TPU delaminated from the textile at the TPU edges and/or the copper-polyimide meanders broke mostly. 


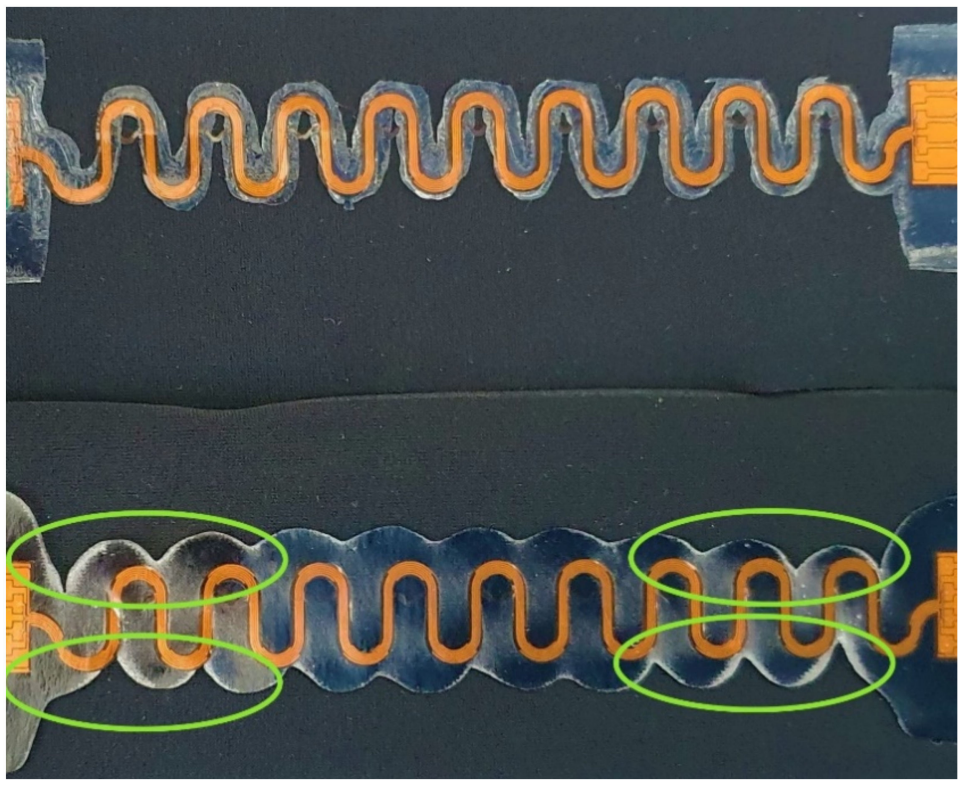

Figure 4. Melting area difference of different versions. Up: Version 1 after lamination and tensile tests. Down: Version 4 after lamination and tensile tests. Circled areas indicate higher stress areas where TPU delaminated from the edges and/or the copper-polyimide meanders broke.

Wearability. Testing for freedom of movement, series on tensile tests was conducted based on ISO 20932-1:2018 standard (Figure 3) [26]. The tests compared plain knit fabric swatches to the same sizes swatch samples with integrated electronic circuits. Most of the measurement points were taken at the test cycles' midpoint (at 12\% strain) (Figure 5).

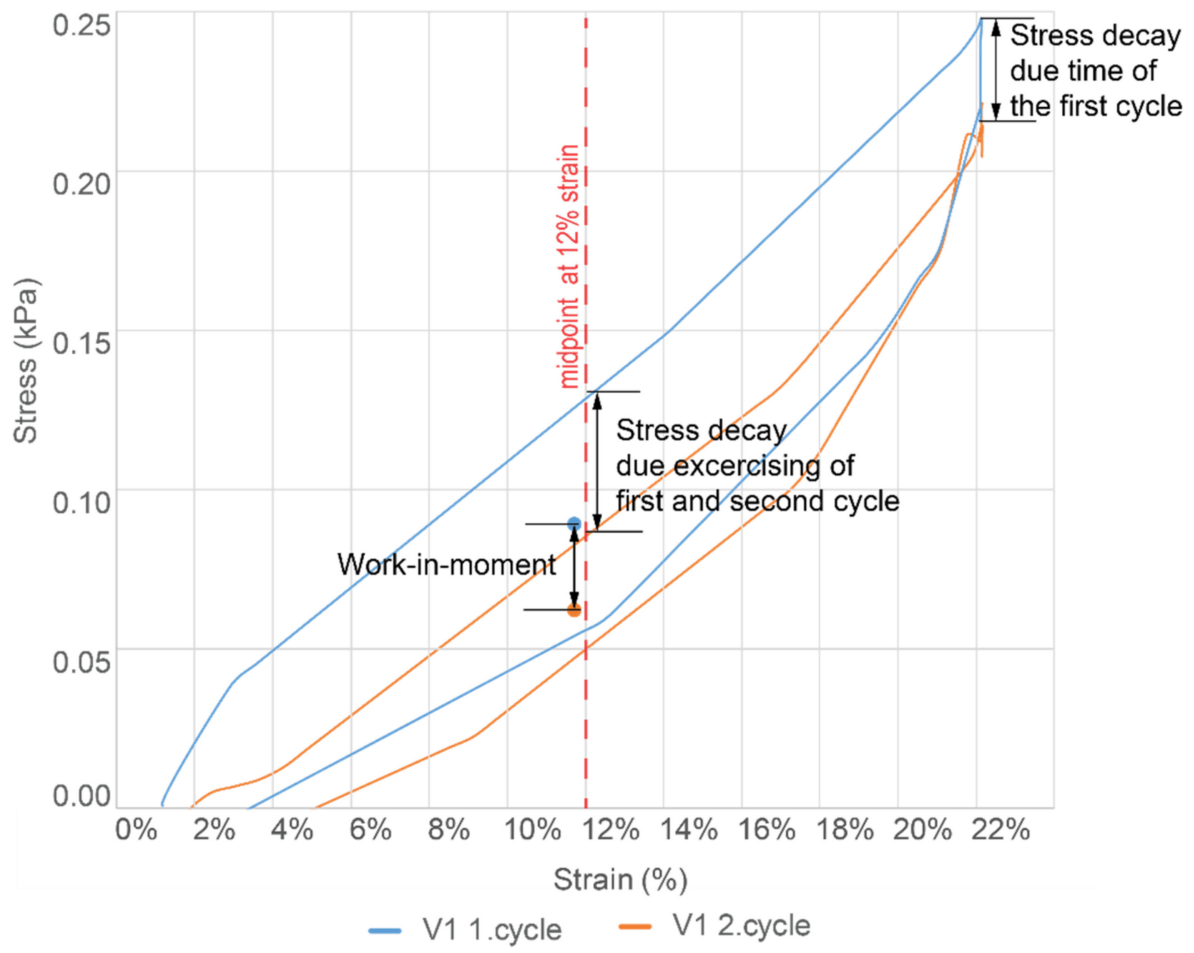

Figure 5. Stress-Strain curve example of the first two cycles from V1, indicating the midpoint position at strain $12 \%$, which was used as the measuring point for determining Young's modulus (E) and Work-in-moment (WiM). Three characteristics and where they are measured is also shown. 
For comparison, three characteristics were considered: Young's modulus $(E)$, Stress decay due to time $\left(\sigma_{t}\right)$, and Work-in-Moment (WiM). All the measurements showed are the average of 5 samples in the sample batch (see Figures 5 and 6).

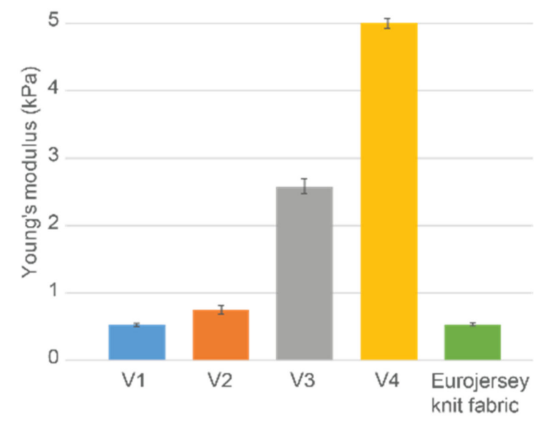

(a)

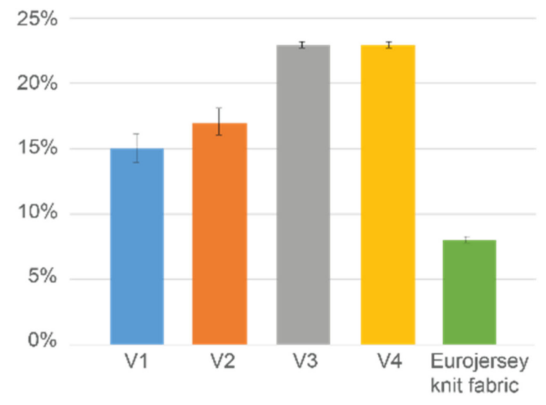

(b)

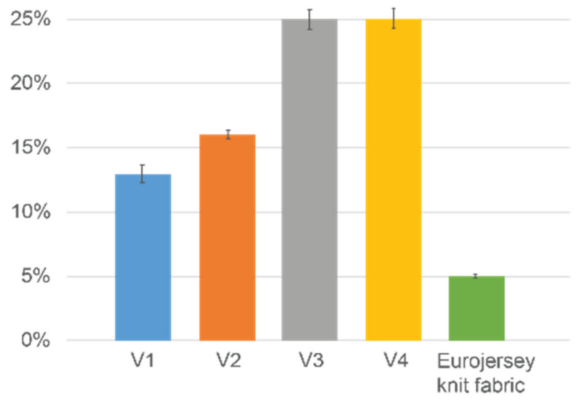

(c)

Figure 6. (a) Young's modulus comparison. (b) Stress decay after $10 \mathrm{~s}$ holding period in 100th tensile test cycle. (c) WiM difference between first and last tensile test cycle.

1. Young's modulus $(E)$, measuring and comparing the elasticity between different samples at the midpoint (12\% strain point).

Based on the tensile tests' data, strain $(\varepsilon)$, stress $(\sigma)$ and Young's modulus $(E)$ were calculated:

$$
E=\frac{F / A}{l_{\Delta} / l_{0}}=\frac{\sigma}{\varepsilon}
$$

where

$F$ is the force exerted on the sample during the tensile test, measured in Newton $(\mathrm{N})$,

$A$ is the actual cross-sectional area in $\mathrm{mm}^{2}$,

$l_{\Delta}$ is the change in length in $\mathrm{mm}$,

$l_{0}$ is the original length of the sample in $\mathrm{mm}$,

$\varepsilon$ is strain,

$\sigma$ is uniaxial stress in $\mathrm{kPa}$.

The Young's modulus was calculated based on the tensile test last cycle values at the strain's midpoint. Figure 6a presents Young's modulus comparison of various stacks in test samples and the plain knit fabric (last column). It was seen that the V1 stack on the knit fabric and the plain fabric have very similar values. Thus, the V1 stack has very little or no effect on the stretchability compared to the plain knit fabric.

Contrary to V1, V4 Young's modulus is over five times larger, making the textile extremely stiff. The melted TPU stack used in V4 is also 4 times thicker than in V1, which affects the stretchability and elasticity of the whole sample. The TPU thickness also means that the melting area is larger, and the meander-shaped TPU melts more together than V1 or V2 (see also Figure 4, Table 3).

2. Stress decay due time $\left(\sigma_{t}, \%\right)$, measuring the maximum load of the last cycle before and after the $10 \mathrm{~s}$ holding period [26].

The goal was to show how much the force changed over the holding period, indicating the ageing of the sample and how elastic or plastic it is. Latter can be additionally defined by measuring the sample length before and after the test (while maintaining a constant load) to check the change in the sample length.

Stress decay due time $\left(\sigma_{t}, \%\right)$ was calculated as follows:

$$
\sigma_{t}=\frac{L_{\max b}-L_{\operatorname{maxa}}}{L_{\operatorname{maxb}}} \times 100 \%
$$

where 
$L_{\text {maxb }}$ is the maximum load of the last cycle before the $10 \mathrm{~s}$ holding period,

$L_{\text {maxa }}$ is the maximum load of the last cycle after the $10 \mathrm{~s}$ holding period.

Figure $6 \mathrm{~b}$ exemplifies stress decay after the $10 \mathrm{~s}$ holding period in the last cycle of the tensile test. Results indicate that although V1 and V2 have almost twice the stress decay (15-17\%) compared to the plain knit fabric, V3 and V4 stress decay over the holding period is even larger and amounts to around 23\%. It aligns with Young's modulus graph by showing that more elastic samples (requiring less force to elongate them) also have less force decay and can keep their original shape for a longer time.

Moreover, it was observed that the force decay after some layering did not change, as seen in V3 and V4, showing similar results while V1 and V2 still had a difference. The question should be investigated more deeply to see from which layering onwards decay difference ceases to matter.

3. Work-in-Moment (WiM, \%), measuring and comparing the hysteresis at the midpoint (12\% strain point) between different cycles and checking how fast and/or intensively it changes.

WiM enables the comparison of hysteresis of different samples and cycles. The main aim of WiM was to see how long it takes each stack to stabilize the hysteresis loop and keep the area similar to coming stretch cycles.

Work-in-moment (WiM, \%) was calculated as follows:

$$
W i M=\frac{\left(\sigma_{1}-\sigma_{2}\right)}{\sigma_{1}} \times 100 \%,
$$

where

$\sigma_{1}$ is the maximum load of the first cycle in comparison, at the midpoint, $\sigma_{2}$ is the maximum load of the second cycle in comparison, at the midpoint.

Figure $6 \mathrm{c}$ shows the WiM difference between the first and hundredth (last) tensile test cycle.

Thus, the results obtained to the chart were calculated as follows:

$$
\text { WiM } M_{1 s t} \text { cycle }-W i M_{100 t h} \text { cycle, }
$$

That would indicate how stable and elastic each sample stack is compared to plain fabric. While V1 and V2 hysteresis loop difference in the plain fabric is 2-3 times larger, V3 and V4 are 5 times larger. It also shows how the hysteresis loop size was also greatly different between thicker and thinner samples. The area of each loop was considerably different, although it was observed that the proportionally the loop stabilized similarly,

The graph also aligns with the stress decay results, indicating how V1 is more elastic. Moreover, after a certain layer thickness and melting area, as in samples V3 and V4, the plastic properties stay the same, and hysteresis loop changes stay similar (as it was also in stress decay results).

Figure 7 displays how plastic and inelastic the V4 sample is, while the V1 sample shows little to no changes in shape after 100 cycles of $20 \%$ elongation. It was seen how the larger melting area of thicker TPU stacks on V3 and V4 create considerably more restriction and plastic properties and behaviour. 


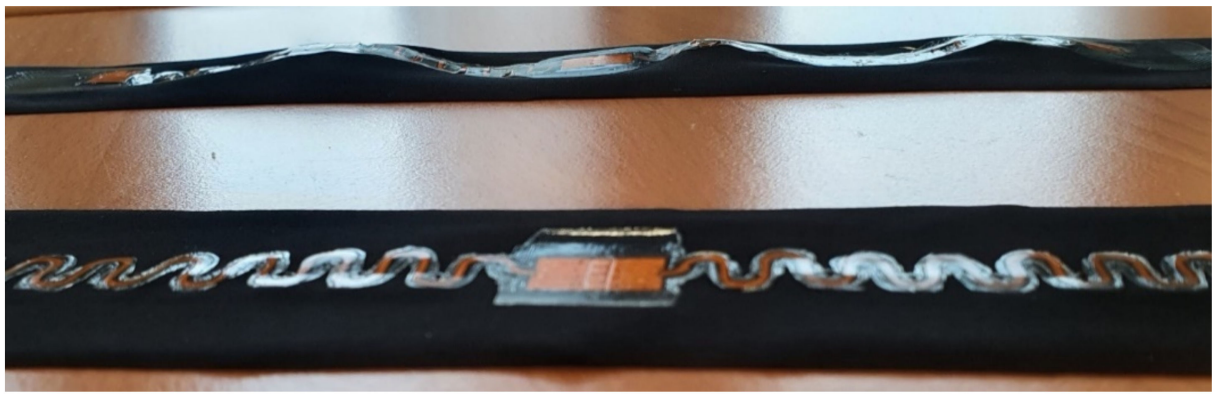

Figure 7. Elasticity difference of V1 and V4 samples. Up: V4 sample after 100 tensile test cycles. The laminated circuit is distorted together with the fabric. Down: V1 sample after 100 tensile test cycles. No distortions into the lamianated circuit or fabric were seen.

Reliability. Reliability to domestic washing procedure was tested based on ISO 63302012 standard (Table 4) [7]. The main goal was to complete 25 washing cycles without introducing errors in the circuit. After every wash cycle, the circuit functionality was evaluated using a multimeter. Electrical continuity of the $\mathrm{Cu}$ metal tracks was measured. After reaching five successful washing cycles, measurements were taken every two washing cycles.

The resistance of each bus system interconnect track stayed stable until failure or end of tests, being on average $16.5 \mathrm{ohm} / \mathrm{m}$ (non-connected additional tracks were not measured). Figure 8 summarises reliability measurement results under the washing tests. V1 sample set had no failures in the sample set and reached 25 washing cycles indicating that the TPU thickness does not necessarily need to be proportional to the level of protection (Figure 8a). In this way, the thinnest stack of Version 1 facilitates successful integration by giving freedom of movement to the entire system and relieving possible buckling. Meanwhile, the V4 sample set had first failures after 5 test cycles, and none of the samples reached 25 cycles (Figure 8).

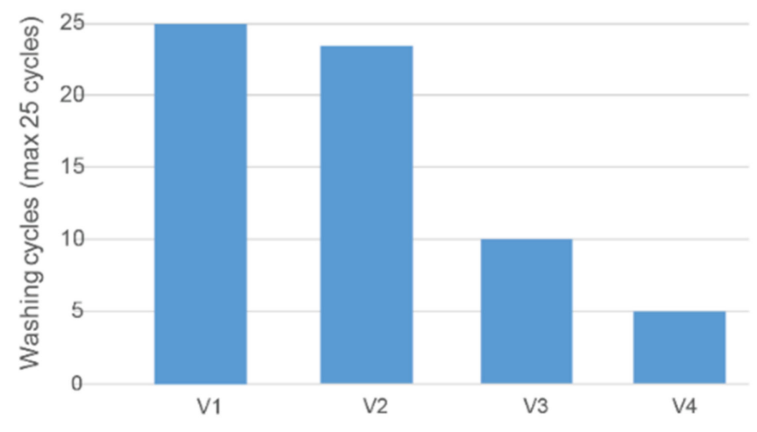

(a)

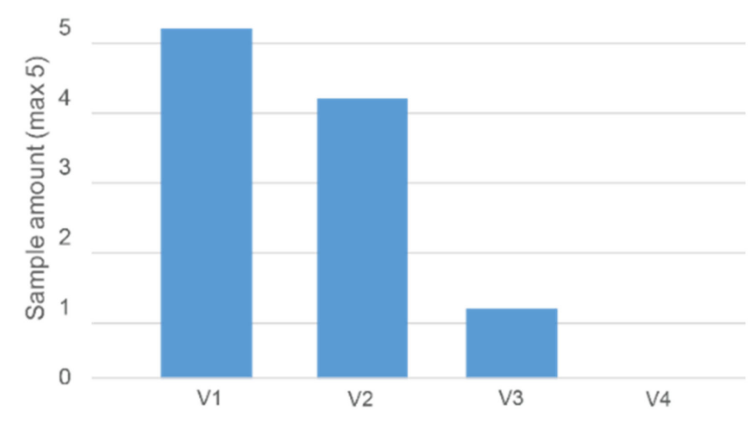

(b)

Figure 8. (a) First failure appearance during washing tests with test samples. (b) Amount of samples per the set of 5 that had no failures after 25 washing cycles.

The copper-polyimide samples buckled and cracked in certain areas due to the stiff TPU only covering part of the textile swatch. Failures in tracks seemed to occur around interposer islands where the circuit transitioned into meanders, indicating a high-stress area and the main point of failure caused by mechanical strain and buckling (Figure 9). The buckling on the thicker stacks (V3, V4) was visible during tensile tests, as seen in Figure 10. In order to minimize the stress, the circuit wants to buckle because of elongation. Buckling can occur with thinner TPU, but thicker and stiffer TPU prevents this, and there is localized stress build-up in the circuit and crack generation in the $\mathrm{Cu}$. Thus, TPU with a thinner and softer layer is the better option for comfort while still providing adequate protection against external factors, like wear and tear and humidity. 

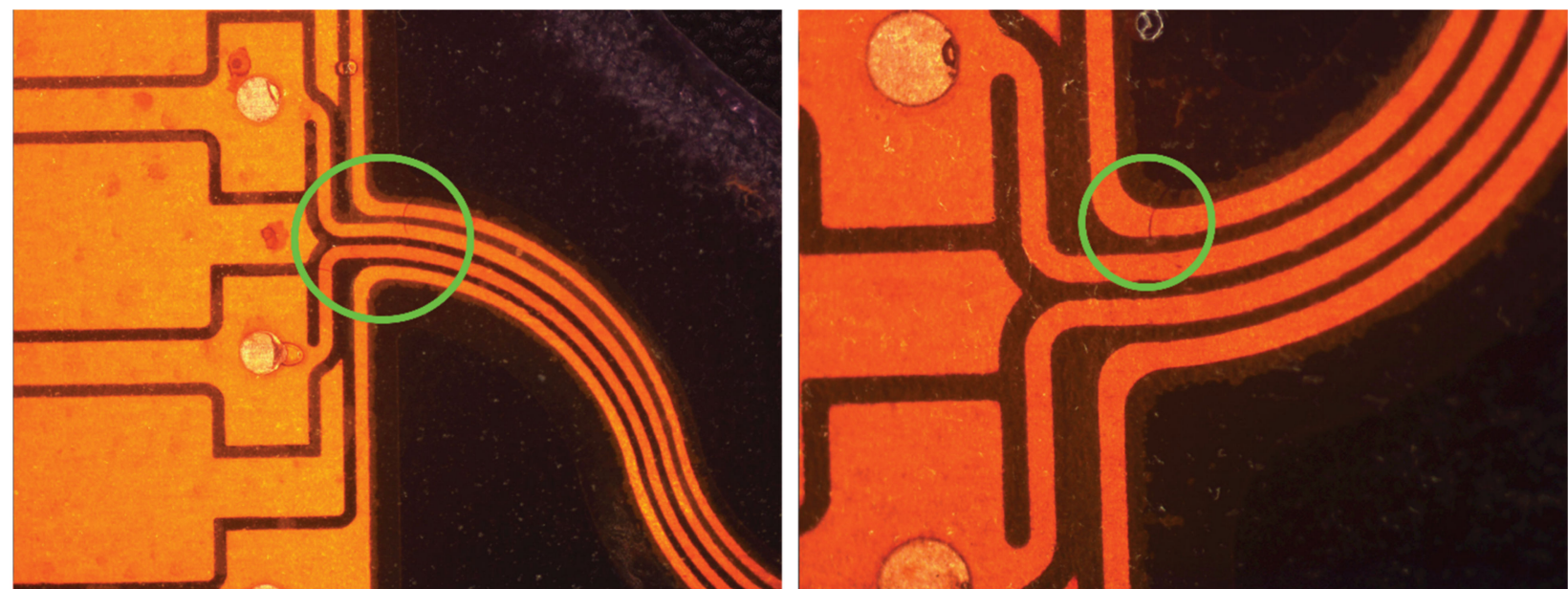

Figure 9. V4 test batch samples with microcracks after washing tests.

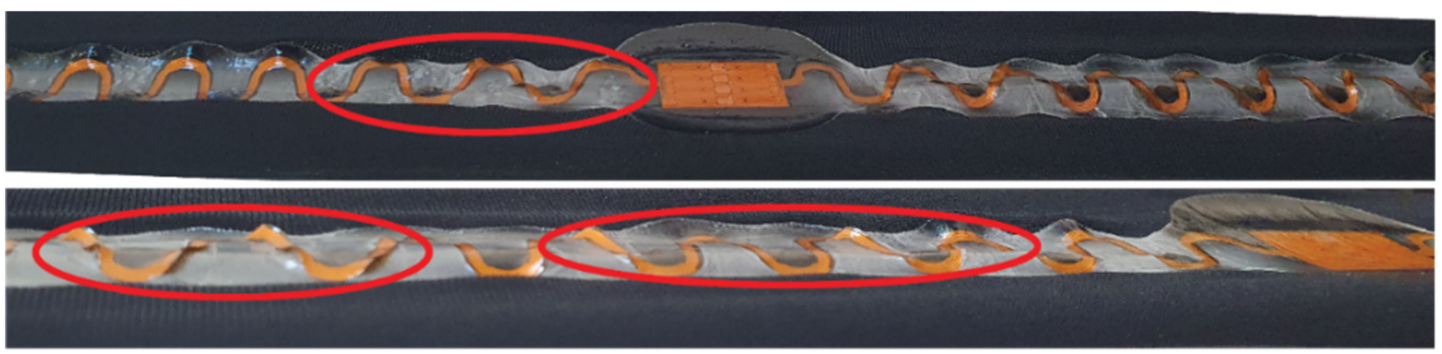

(a)
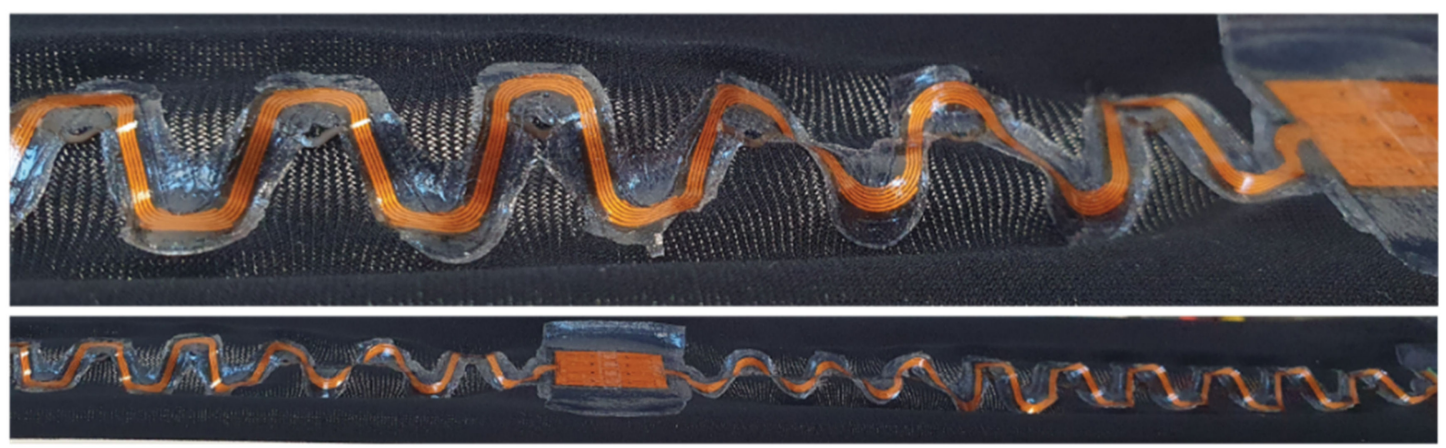

(b)

Figure 10. (a) V4 under 20\% stretch, circled areas highlight buckling. (b) V1 under $20 \%$ stretch, the laminated circuit buckles together with the fabric but does not release or delaminate from it.

Overall, it was seen that stiffer and thicker TPU stack limited the sample movement and created specific stress areas, as seen in Figure 4. However, that contradicts previous results where thicker TPU stacks provided additional durability to samples [25].

\section{Discussion}

Wearability. As discussed in the beginning, wearability is a broad concept. It is still often tested mainly with subjective user tests which need accurate questionnaires and interpretation. The current study based the wearability test on the tensile test and examined it mainly on comparing the plain knit fabric versus knit fabric with an integrated electronic circuit based on three characteristics: Young's modulus, stress decay due time and Work-in-Moment.

It was clear that the V3 and V4 samples are much more plastic than the V1 and V2 based on samples' shape and length after the tests (Figure 7) and Young's modulus results 
(Figure 6a). V1 and the plain fabric had very similar Young's modulus results, showing that the stretchability of either can be interchangeable. A subjective users' study is typically conducted to determine comfort level, and these results may be used to strengthen or complement the study.

The decay of the force changes in steps-7\% comparing the plain knit fabric to the $\mathrm{V} 1$ and $8 \%$ comparing V1 to V4. It was observed that the TPU layering increases the force decay, but the more elastic samples (V1, V2) still had considerably lower deterioration. WiM graph also aligns with the stress decay results and show how the V1 stack gives the most elastic version. It was observed that most plastic stacks (V3, V4) had the same results in both cases, indicating how beyond a specific TPU melting area and thickness, the plastic properties stay very similar.

Figure 10a displays how tensile tests brought out visible buckling on the thicker stacks. V4 meanders warped under stress and showed possible delamination points (light areas in Figure 10a). However, the V1 stack visibly had no delamination or extra buckling out of the fabric plane, and the whole laminated system moved with the knit fabric (Figure 10b). Thus, using thinner TPU layers creates no specific stress areas on the circuit, resulting in the absence of failures.

Plastic properties and fast ageing on most clothing are not accepted. Thus, these measurable properties could also additionally support the possible comfort level of the future garment. Still, it needs to be kept in mind that e-textiles application areas vary tremendously. High stiffness that could also offer support or additional reinforcement in certain areas on the body can be used in specific use cases, e.g., in work or medical clothing.

Reliability. Stretchable electronics encapsulated with various TPU layering on textiles and their durability to washing procedures were also tested in previous work [25]. The double-layered TPU with the same meander design was more successful in the previous study. However, the prior work did not test meanders with non-connected extra copper together with one layer of TPU in the meander width nor used the meander-shape structured TPU. Figure 11 displays the different layering and TPU area methods in the two studies. In the earlier work, it was apparent that the increased number of layers of TPU (either $100 \mu \mathrm{m}$ or $250 \mu \mathrm{m}$ thick) was one of the factors creating more durable integration.

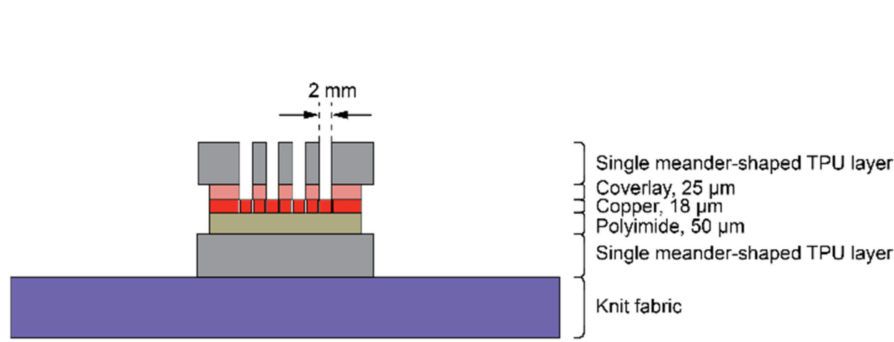

(a)

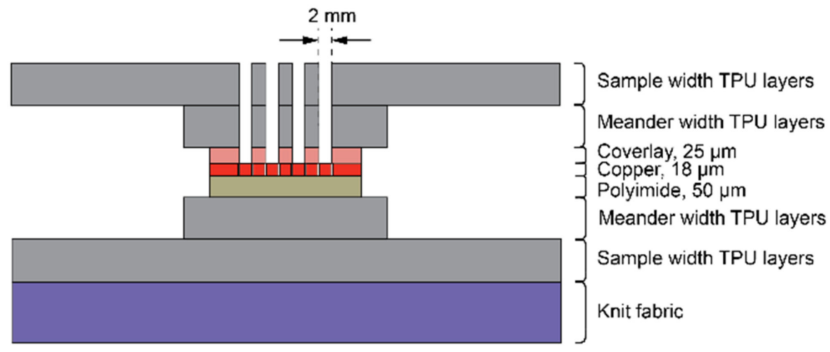

(b)

Figure 11. Layering system of samples. (a) V1 and V3 layering systems in the current tests. (b) Most successful TPU layering system in the previous work, reproduced with permission [25].

Reviewing the earlier samples (Figure 11b), it appears that having a uniform, nonpatterned TPU layer in the TPU area on the whole sample decreases the stress areas around the weakest points observed around interposer and meander junction in any stacks version. While the V4 samples melting area in the current study is more extensive, it still does not cover most of the textile and creates a lot of stress around interposer joints (Figures 4 and 9).

Figure $11 \mathrm{~b}$ also demonstrates how a larger TPU cover protects the additional smaller TPU area in the previous work tests samples. In this way, it was seen that the copperpolyimide system is less prone to buckling and cracking. Going back to visible buckling during the current tensile tests, it was clear how a reduced yet highly stiff laminated area could not avoid buckling in V3 and V4 samples (Figure 10a). 
Presumably, unifying the TPU area creates fewer stress areas. However, it appears that if the TPU layers are minor in surface area and/or thin enough, the uniformity of the whole sample is not disturbed. Thus, the elasticity (cf Figure 6a) stays similar or the same as without the TPU layers. Nevertheless, when the TPU was used to cover the entire sample without shaping/patterning the covered area in any way, the stretchability and elasticity were severely hindered. Figure 12 last 3 bars display Young's modulus difference in previous samples compared to the plain knit fabric. The least stiff sample (with lowest thickness TPU used, Young's modulus $9 \mathrm{kPa}$ ) still does not emulate the stiffest samples (V4) (Young's modulus $5 \mathrm{kPa}$, see Figure 12) in current work.

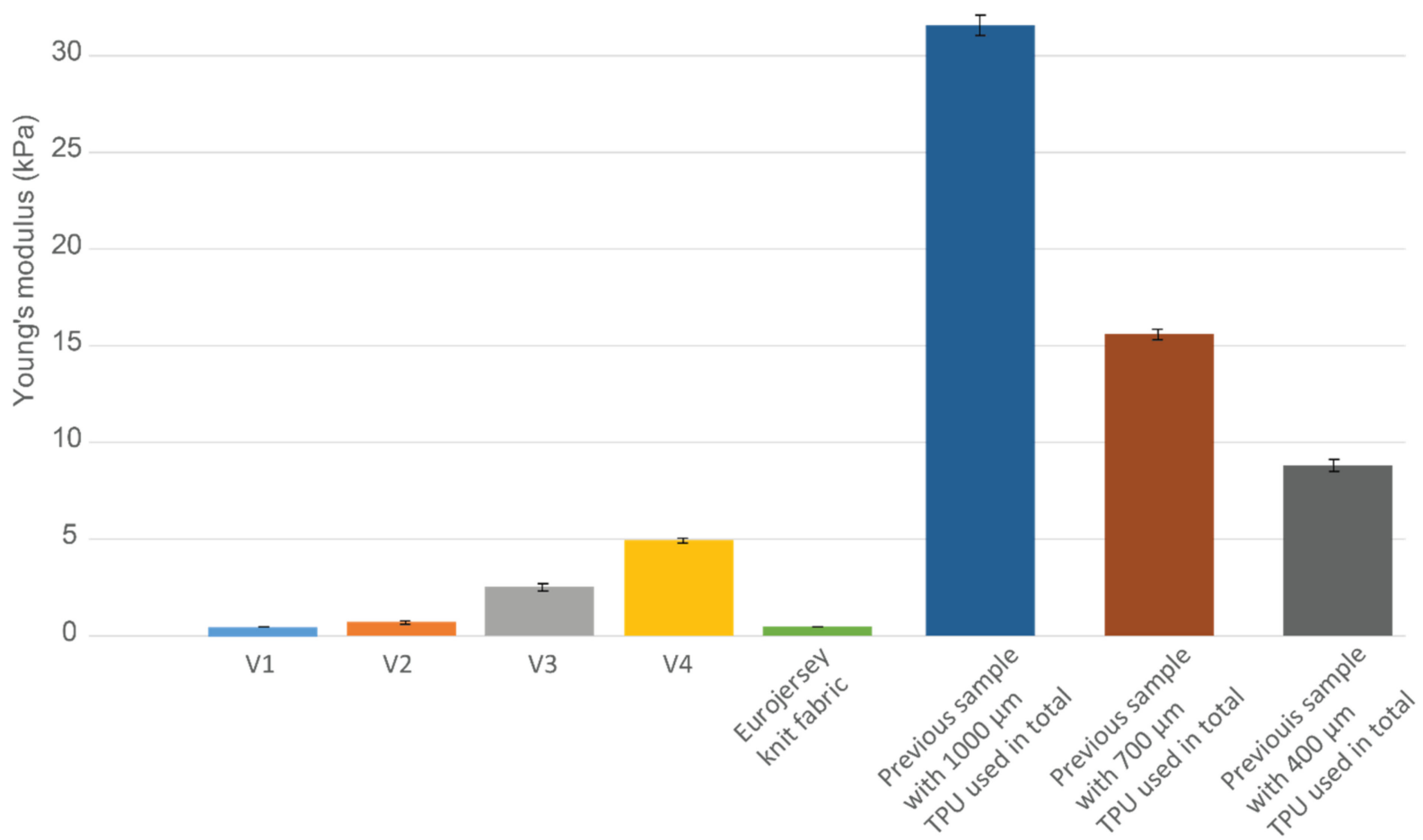

Figure 12. Young's modulus comparison of current samples, plain knit fabric and previous work samples.

It is essential to note that the TPU cover area needs to be considered based on application needs, as mentioned before. Washing reliability compared to the freedom of movement can be more important in certain fields and vice versa. The $250 \mu \mathrm{m}$ TPU melting area was considerably larger in any case. Thus, it would be useful to determine if it can be precisely shaped to cover very specific areas and, by that, gain more flexibility.

Moreover, it is important to note the possible misalignment issues that may happen during the lamination process. Figure 4 lower photo shows the small misalignment around the interposer. The deformations during the lamination process and TPU geometry with the material handling process might create difficulties affecting the final reliabilty and wearability. The possible solutions to avoid the possible misalignment need to be researched further, together with efficient fabrication methods for larger volumes manufacturing. For example, laser-cutting the TPU together with meander circuits needs to be tested.

\section{Conclusions}

This study tested four different TPU stacks on copper-polyimide meanders for the e-textile integration method. The aim was to research each stack's wearability (freedom of movement) and domestic washing reliability.

Since the thinnest stack (V1) and plain knit fabric elastic modulus were compatible, future work can include comparative end-user studies. It was seen how the thinnest stack had the most similar properties to plain fabric, which exhibited an increased level 
of comfort and freedom of movement. A subjective end-user study could indicate if the comfort level stays still the same with or without the circuit lamination.

Interestingly, the thinnest stack was also most durable in washing tests. It was seen how increased freedom of movement also decreased specific stress areas that were obvious in thicker stacks. Moreover, the thicker TPU melting areas were considerably larger than in the case of thinner TPU stacks, thus reducing flexibility and enhancing the crack formation around interposer and meander tracks' transition areas.

A further study could assess the effects of an additional knit fabric layer on top of the circuit. So far, the research has used only TPU layers in the integration process. However, the additional fabric layer would most probably hinder the stretchability but also increase durability and aesthetics. Still, the additional fabric layer on top could help prolong the product's overall lifetime since delamination of TPU for repairs and reuse of parts could be done more easily and efficiently. Moreover, a more efficient and accurate lamination method on top of the meander circuits will be researched and examined.

Author Contributions: Conceptualization, P.V., F.B. and J.V.; methodology, P.V.; validation, P.V., F.B. and J.V.; formal analysis, P.V., F.B. and J.V.; investigation, P.V., F.B. and J.V.; resources, F.B. and J.V.; data curation, P.V.; writing — original draft preparation, P.V.; writing—review and editing, P.V., F.B. and J.V.; visualization, P.V, F.B. and J.V.; supervision, F.B. and J.V. All authors have read and agreed to the published version of the manuscript.

Funding: This research received no external funding.

Informed Consent Statement: Not applicable.

Conflicts of Interest: The authors declare no conflict of interest.

\section{References}

1. Kamitis. Smart Textiles-Applications, Technologies and Markets: 2017-2022; Kamitis: Lyon, France, 2017.

2. Ruck, A. Information and Stakeholders' Day on Wearables; European Commission: Brussles, Belgium, 2015.

3. Vercruysse, N. Strategic Foresight: Towards the 3rd Strategic Programme of Horizon 2020; European Commission: Luxembourg, 2015.

4. Buechley, L.; Eisenberg, M. The LilyPad Arduino: Toward Wearable Engineering for Everyone. IEEE Pervasive Comput. 2008, 7, 12-15. [CrossRef]

5. Van Langenhove, L.; Hertleer, C. Smart clothing: A new life. Int. J. Cloth. Sci. Technol. 2004, 16, 63-72. [CrossRef]

6. AATCC. Test Method for Dimensional Changes of Fabrics after Home Laundering. 2018. Available online: https://members. aatcc.org/store/tm135/543/ (accessed on 2 December 2021).

7. ISO. ISO 6330:2012-Textiles-Domestic Washing and Drying Procedures for Textile Testing. 2012. Available online: https: //www.iso.org/obp/ui\#iso:std:iso:6330:ed-4:v1:en (accessed on 2 December 2021).

8. Linz, T.; Kallmayer, C.; Aschenbrenner, R.; Reichl, H. Embroidering electrical interconnects with conductive yarn for the integration of flexible electronic modules into fabric. In Proceedings of the Ninth IEEE International Symposium on Wearable Computers (ISWC'05), Washington, DC, USA, 18-21 October 2005; pp. 86-89.

9. Uz Zaman, S.; Tao, X.; Cochrane, C.; Koncar, V. Launderability of Conductive Polymer Yarns Used for Connections of E-textile Modules: Mechanical Stresses. Fibers Polym. 2019, 20, 2355-2366. [CrossRef]

10. Ryan, J.D.; Mengistie, D.A.; Gabrielsson, R.; Lund, A.; Müller, C. Machine-Washable PEDOT:PSS Dyed Silk Yarns for Electronic Textiles. ACS Appl. Mater. Interfaces 2017, 9, 9045-9050. [CrossRef] [PubMed]

11. Liu, W.; Shangguan, D.; Lee, J.C. Evaluation of Launderability of Electrically Conductive Fabrics for E-Textile Applications. IEEE Trans. Compon. Packag. Manuf. Technol. 2020, 10, 763-769. [CrossRef]

12. Tao, X.; Koncar, V.; Huang, T.-H.; Shen, C.-L.; Ko, Y.-C.; Jou, G.-T. How to Make Reliable, Washable, and Wearable Textronic Devices. Sensors 2017, 17, 673. [CrossRef] [PubMed]

13. Linz, T.; von Krshiwoblozki, M.; Walter, H. Novel Packaging Technology for Body Sensor Networks Based on Adhesive Bonding A Low Cost, Mass Producible and High Reliability Solution. In Proceedings of the 2010 International Conference on Body Sensor Networks, Singapore, 7-9 June 2010; pp. 308-314.

14. Toeters, M.; de Kok, M.; Bonvie, M.; Enzo, K. Closed Loop Smart Athleisure Fashion Project. Available online: http://www.bywire.net/wear-sustain-closed-loop-smart-atheleisure-fashion/ (accessed on 2 December 2021).

15. Rotzler, S.; Kallmayer, C.; Dils, C.; von Krshiwoblozki, M.; Bauer, U.; Schneider-Ramelow, M. Improving the washability of smart textiles: Influence of different washing conditions on textile integrated conductor tracks. J. Text. Inst. 2020, 111, 1766-1777. [CrossRef] 
16. Wang, Q.; Toeters, M.; Chen, W.; Timmermans, A.; Markopoulos, P. Zishi: A Smart Garment for Posture Monitoring. In Proceedings of the 2016 CHI Conference Extended Abstracts on Human Factors in Computing Systems, San Jose, CA, USA, 7-12 May 2016; 2016; pp. 3792-3795.

17. Slater, K. Human Comfort; Charles, C., Ed.; Thomas Publisher: Springfield, IL, USA, 1985; p. 249.

18. Bartels, V.T. 9-Physiological comfort of sportswear. In Textiles in Sport; Shishoo, R., Ed.; Woodhead Publishing: Cambridge, UK, 2005; pp. 177-203.

19. Lefere, P. Fandom Markets. TCBL J. 2019, 1, 1. Available online: https://press.ierek.com/index.php/TCBL/article/view/570 (accessed on 2 December 2021).

20. Roy Choudhury, A.K.; Majumdar, P.K.; Datta, C. 1-Factors affecting comfort: Human physiology and the role of clothing. In Improving Comfort in Clothing; Song, G., Ed.; Woodhead Publishing: Cambridge, UK, 2011; pp. 3-60.

21. Rantakari, J.; Inget, V.; Colley, A.; Häkkilä, J. Charting Design Preferences on Wellness Wearables. In Proceedings of the 7th Augmented Human International Conference 2016, Geneva, Switzerland, 25-27 February 2016; p. 28.

22. Abdallah, M.; Clevenger, C.; Vu, T.; Nguyen, A. Sensing occupant comfort using wearable technologies. In Proceedings of the Construction Research Congress, San Juan, Puerto Rico, 31 May-2 June 2016; pp. 940-950.

23. Bodine, K.; Gemperle, F. Effects of functionality on perceived comfort of wearables. In Proceedings of the Seventh IEEE International Symposium on Wearable Computers, White Plains, NY, USA, 21-23 October 2003; p. 57.

24. Knight, J.F.; Baber, C.; Schwirtz, A.; Bristow, H.W. The Comfort Assessment of Wearable Computers. In Proceedings of the ISWC, Seattle, WA, USA, 10 October 2002; pp. 65-74.

25. Veske, P.; Bauwens, P.; Bossuyt, F.; Sterken, T.; Vanfleteren, J. Development and Washing Reliability Testing of a Stretchable Circuit on Knit Fabric. Appl. Sci. 2020, 10, 9057. [CrossRef]

26. ISO. ISO 20932-1:2018 - Textiles—Determination of the Elasticity of Fabrics-Part 1: Strip Tests. 2018. Available online: https: //www.iso.org/standard/69489.html (accessed on 2 December 2021). 